\title{
Perancangan dan Realisasi Generator Ozon menggunakan Metoda Pembangkitan Tegangan Tinggi Bolak - Balik (AC)
}

\author{
WALUYO ${ }^{1}$, DERIL ALVIAN PERMANA ${ }^{1}$, SITI SAODAH ${ }^{2}$ \\ 1. Teknik Elektro Institut Teknologi Nasional \\ 2. Teknik Konversi Energi Politeknik Negeri Bandung \\ Email : waluyo@itenas.ac.id
}

\begin{abstract}
ABSTRAK
Pemanfaatan teknologi ozon pada berbagai sektor telah menunjukkan kegunaan dan keunggulan dari pemanfaatan ozon.Salah satu cara yang dapat digunakan untuk menghasilkan ozon melalui peluahan muatan listrik dengan korona discharge. Metoda perancangan generator ozonmenggunakan pembangkitan tegangan tinggi dari trafo dengan variasi tegangan $\pm 3000 \mathrm{~V} \& \pm 4000 \mathrm{~V}$, laju alir oksigen (1 dan 3 liter/menit), dan waktu ozonasi (5; 10; 15; 20; 25 dan 30 menit) dan mengatur jarak antar batang konduktor 0,3 cm. Produk ozon dialirkan pada air bersih dan dihitung konsentrasi sisa ozonnya menggunakan larutan indigo kolorimetri. Hasil menunjukkan bahwa semakin menurunnya laju alir oksigen, konsentrasi ozon meningkat. Peningkatan tegangan output akan menambah besar medan listrik yang dihasilkan, sehingga konsentrasi ozon meningkat. Besar tegangan yang berhasil dibangkitkan sebesar $3370 \mathrm{~V}$ dan $4324 \mathrm{~V}$. Konsentrasi maksimum ozon yang terbentuk adalah $0.088 \mathrm{mgO}_{3} /$ liter pada voltase $4324 \mathrm{~V}$ dan laju alir oksigen 1 liter/menit. Konsentrasi minimum ozon yang terbentuk adalah 0,012 $\mathrm{mgO}_{3} / \mathrm{L}$ pada voltase 3370 dan laju alir oksigen 3 liter/menit.
\end{abstract}

Kata Kunci : indigo kolorimetri, korona discharge,medan listrik, ozon, ozon generator

\section{ABSTRACT}

Using of ozone technology at various sectors have shown excellence and usefulness of ozone. One of the way to produce ozone is by electric discharge with corona discharge. The design method of ozone generator by generating high voltage from the transformer with voltage variation $\pm 3000 \mathrm{~V}$ and $\pm 4000 \mathrm{~V}$, the oxygen flow rate ( 1 and 3 liters / min ), and the time of ozonation ( $5 ; 10 ; 15 ; 20 ; 25$ and $30 \mathrm{~min}$ ) and adjust the distance between the conductor rod $0.3 \mathrm{~cm}$. Product ozone water flowed in and calculated the concentration of residual ozon use solution indigocolorimetri. Result indicated that the decreasing of oxygen flowrate leads ozon concentration increase. By increasing of voltage variation, the electric field increasingly large, the more the results of ozone is formed. Large voltage successfully raised at $3370 \mathrm{~V}$ and $4324 \mathrm{~V}$. The maximum concentration of ozone is formed is $0.088 \mathrm{mgO} 3$ / liter at 4324 volts voltage and oxygen flow rate of 1 liter / min. The minimum concentration of ozone is formed is $0.012 \mathrm{mgO3} / \mathrm{L}$ at 3370 voltage and oxygen flow rate of 3 liters / min.

Key word : indigo kolorimetri, korona discharge, electric field, ozon, ozon generator 


\section{PENDALULUAN}

Penumpukan sampah di Tempat Pemrosesan Akhir (TPA) menyebabkan sulitnya mendapatkan air tanah yang bagus dan bersih untuk lingkungan sekitar TPA. Penumpukan sampah dengan waktu yang lama dapat menimbulkan keluarnya cairan hasil pembusukan sampah tersebut, cairan lindi atau cairan hasil dari pembusukan sampah ini menimbulkan bau yang sangat menyengat dan dapat mencemari ketersediaan air tanah dan lingkungan sekitarnya. Kerusakan lingkungan yang sebagian besar disebabkan oleh manusia mendorong untuk memperhitungkan dampak buruk pencemaran lingkungan sampai batas serendah mungkin.

Salah satu kebutuhan pokok manusia adalah tersedianya air bersih. Selama ini untuk memperoleh air bersih adalah dengan cara menambahkan zat khlorin. Penggunaan khlorin tidak terbatas untuk menyediakan air bersih, tetapi berkembang pada setiap jenis kegiatan yang berkaitan dengan desinfektan. Dampak baru yang dirasakan adalah khlorin dicurigai sebagai zat karsinogen yang dapat menimbulkan penyakit kanker. Kesadaran untuk meninggalkan khlorin berhasil dengan ditemukannya senyawa ozon yang ternyata mempunyai potensi yang lebih kuat dengan dampak yang sangat kecil karena beberapa sifat ozon yang positif yaitu waktu paruh pendek dan peluruhannya adalah oksigen yang dibutuhkan manusia, sehingga ozon adalah zat desinfektan yang ramah lingkungan. Penggunaan ozon sebagai desinfektan pengganti khlorin berjalan dengan pesat dengan jangkauan yang sangat luas. Dari pemenuhan air minum, sterilisasi buah, sayur, daging, ikan, telur, sterilisasi piranti kedokteran, terapi, pengolahan limbah tekstil, kertas dan lain sebagainya.

Pemanfaatan teknologi ozon dapat digunakan untuk mengurangi kandungan bahan berbahaya dan beracun (B3)seperti logam besi, zat beracun pada pembersih lantai dan lainnya yang terdapat pada cairan yang dihasilkan oleh tumpukan sampah, sehingga air tersebut dapat dengan aman dialirakan menuju sungai dan tidak mencemari lingkungan sekitar. Mengingat akan aplikasi ozon yang mempunyai banyak manfaat, maka pembuatan generator ozon sangat perlu untuk direalisasikan khususnya yang dalam tahap ini akan digunakan untuk perlakuan air.

Sifat ozon di alam yang tidak stabil mengakibatkan ozon tidak dapat dipaketkan untuk dibawa ke suatu tempat, sehingga ozon harus dibuat di tempat yang membutuhkan ozon (Purwadi dkk, 2002). Untuk itu dibutuhkan sebuah alat yang mampu memproduksi ozon dengan waktu yang singkat dan tidak membutuhkan energi yang banyak. Pembangkit ozon terdiri dari dua bagian utama yaitu sumber tegangan AC dan tabung reaktor ozon karena untuk memecah molekul oksigen $\left(\mathrm{O}_{2}\right)$ menjadi ion-ion oksigen $\left(\mathrm{O}^{*}\right)$ dibutuhkan suatu medan listrik yang cukup kuat. Hal ini bisa terjadi apabila oksigen dilewatkan atau dikenai medan listrik yang cukup tinggi (Yusuf dkk, 2008).

Seiring dengan perkembangan teknologi berbasis tegangan tinggi (high voltage), ozon dapat diproduksi pada tekanan udara atmosfer melalui proses lucutan elektron (electron discharge) menggunakan instrumentasi generator ozon. Hingga saat ini, pembentukan ozon dapat dilakukan dengan metoda radiasi sinar-UV, lucutan elektron dan reaksi elektrolisis kimia (Ebbing dan Gammon, 2009). Berdasarkan pada penelitian terdahulu menjelaskan bahwa produksi ozon yang cukup besar dihasilkan melalui metode pelucutan elektron. Berdasarkan latar belakang di atas, maka akan dipelajari cara perancangan generator ozon ini dengan menggunakan metode korona discharge. 


\section{METODOLOGI PERANCANGAN}

\subsection{Langkah Penelitian}

Metodologi penelitian merupakan proses ataupun langkah-langkah yang bertujuan agar penelitian dapat dilakukan secara sistematis. Penelitian dilakukan berdasarkan beberapa tahapan dari awal hingga akhir yang dinyatakan dalam diagram alir seperti pada Gambar 1.

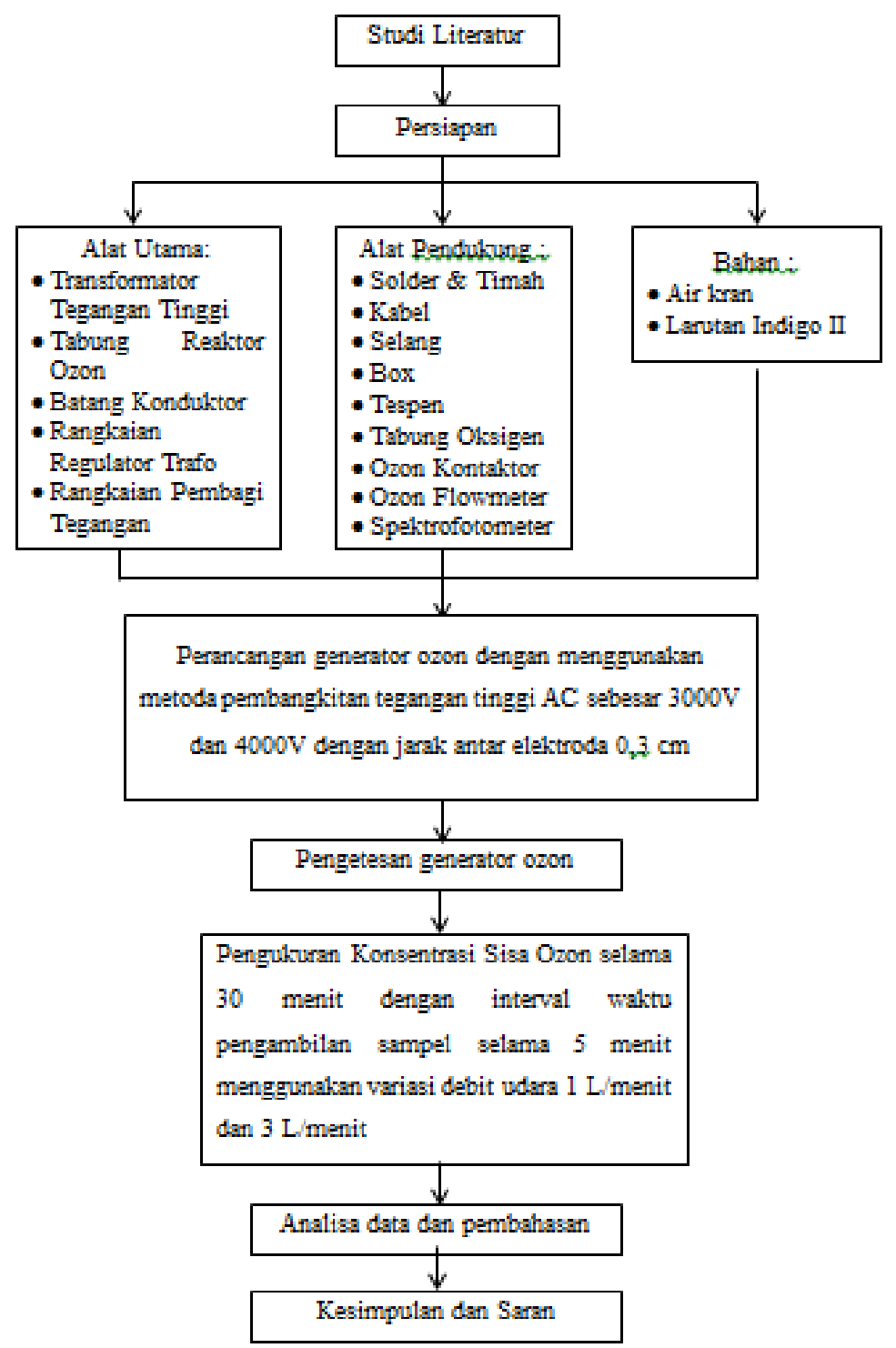

Gambar 1.Blok diagram penjelasan secara umum

\subsection{Persiapan Perancangan}

a. Trafo Tegangan Tinggi

Transformator adalah suatu alat listrik yang dapat memindahkan dan mengubah energi listrik satu atau lebih rangkaian listrik ke rangkaian listrik yang lain, melalui suatu gandengan magnet berdasarkan prinsip induksi-elektromagnet. Transformator adalah alat yang digunakan untuk mengubah tegangan bolak balik (AC) dari suatu nilai tertentu ke nilai yang kita inginkan terdiri dari kumparan primer dan sekunder. Transformator tegangan tinggi berfungsi sebagai sumber pembangkit tegangan tinggi. Pada perancangan ini menggunakan transformator neon tipe 15002/ 30CM produk italy dengan spesifikasi: 
a. Tegangan pada kumparan primer : $240 \mathrm{~V}$

b. Tegangan pada kumparan sekunder: 7,5KV-E-7,5KV

c. Frekuensi : $50 \mathrm{~Hz}$

d. Arus pada kumparan primer: $1,8 \mathrm{~A}$

e. Arus pada kumparan sekunder: $25 \mathrm{~mA}$ (fasa-bumi) / $30 \mathrm{~mA}$ (fasa-fasa)

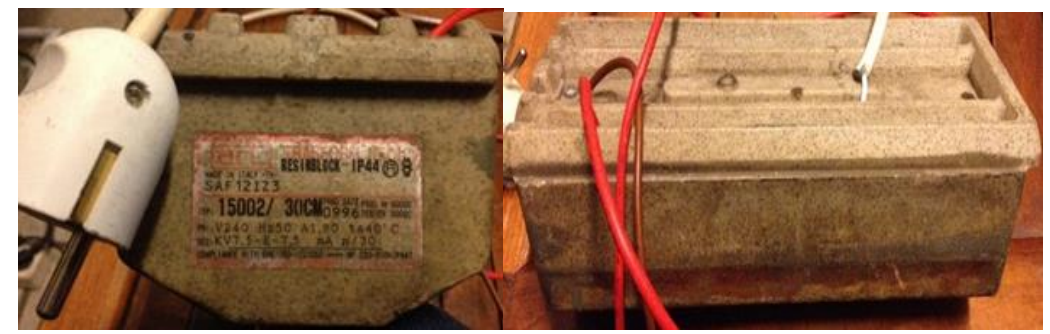

Gambar 2.Trafo Tegangan Tinggi

b. Tabung Reaktor Ozon

Tabung reaktor ozon adalah tabung yang terbuat dari kaca fiberglass yang berfungsi sebagai tempat terjadinya electron discharge. Tabung reaktor ozon ini memiliki panjang $10 \mathrm{~cm}$, dengan tebal $0,1 \mathrm{~cm}$ dan berdiameter $2,5 \mathrm{~cm}$. pada sisi ujung tabung terdapat celah atau lubang yang memiliki ukuran yang sama pada keduanya yang berfungsi sebagai lubang masukan gas oksigen, dan lubang keluaran gas ozon.

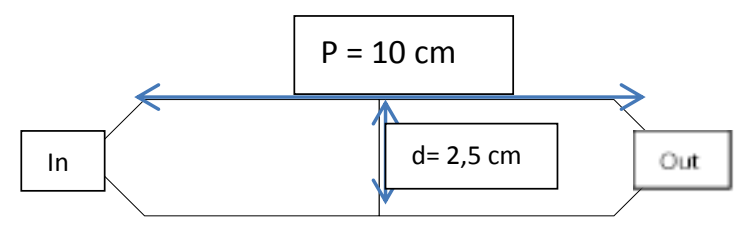

\section{Gambar 3. Reaktor Ozon}

Ozon berasal dari kata Yunani "ozein" yang berarti mencium, hal ini disebabkan karena ozon memiliki bau yang khas. Ozon dapat tercium dengan konsentrasi dari 0,01 ppm (part per million). Ozon merupakan gas yang memiliki bau tajam dan tidak berwarna. Unsur kimia yang terkandung dalam partikel ozon yaitu tiga buah atom oksigen $\left(\mathrm{O}_{3}\right)$ yang membentuk sudut $116^{\circ} 49^{\prime}$. Gas ini biasanya dapat terdeteksi pada konsentrasi 0,01 hingga 0,04 ppm dan ketika konsentrasinya 1,00 ppm baunya sudah sangat tajam.

c. Rangkaian Regulator Trafo

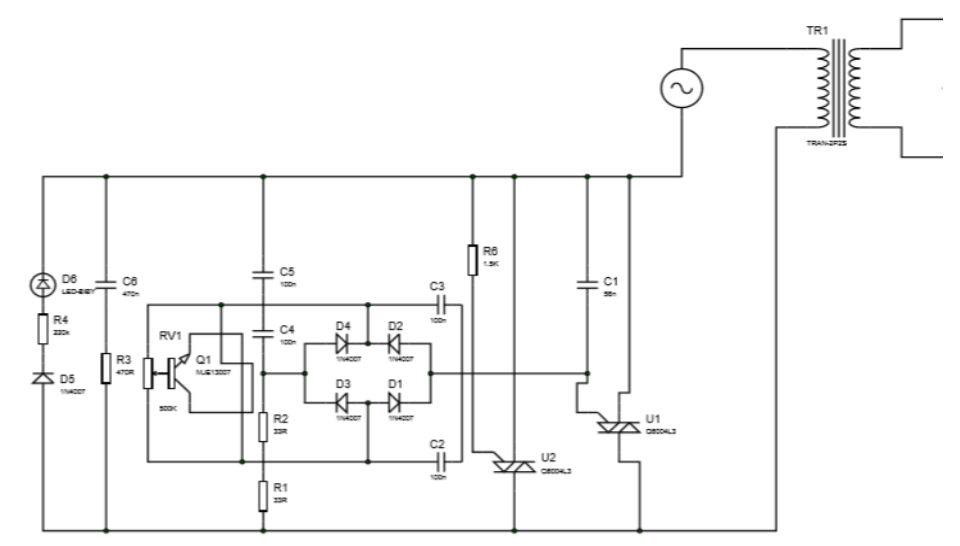

Gambar 4. Rangkaian Regulator Trafo 
Rangkaian ini berfungsi untuk mengatur output trafo sehingga dapat mengeluarkan tegangan trafo sesui dengan keiinginan. Prinsip kerja rangkaian regulator ini adalah menggunakan triac sebagai komponen saklar elektrik atau sebagai komponen switching. Penempatan rangkaian regulator trafo ini ditempatkan pada jalur input trafo. Arus input trafo diatur sehingga tegangan output trafo berubah sesuai dengan arus input yang diatur oleh rangkaian regulator trafo tersebut. Triac akan tersambung (on) ketika ada arus positif kecil melewati terminal gate MT1, dan polaritas MT2 lebih tinggi dari MT1, semakin besar tegangan gate, maka semakin kecil hambatan dan arus yang mengalir melewati triac semakin besar. Pengaturan tegangan gate pada triac berasal dari kaki base yang dihubungkan menuju potensiometer dan kemudian diberikan menuju diode yang disusun secara jembatan atau bridge. Hal ini bertujuan untuk memberikan tegangan bias pada pin gate. Led terpasang sebagai indikator bahwa rangkaian regulator tersambung (on).Masing masing alat utama dirangkai menjadi rangkaian skematis seperti pada Gambar 5.

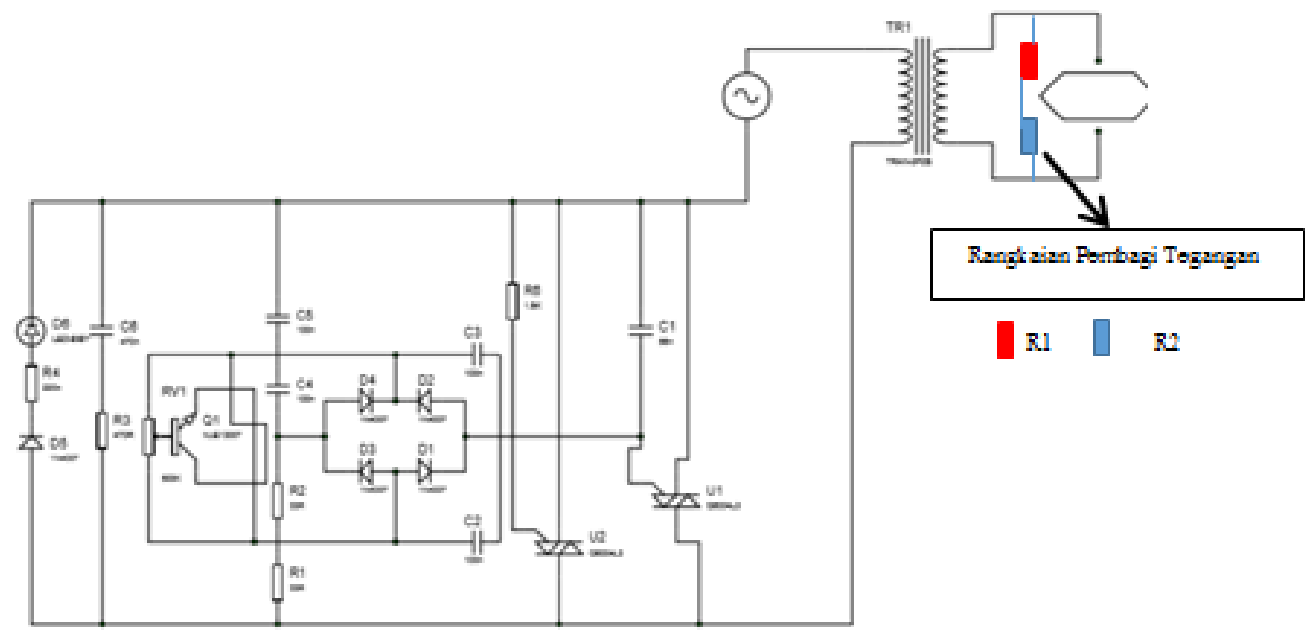

Gambar 5.Rangkaian skematis

Gambar 5. Menjelaskan rangkaian skematis dari penyusunan rangkaian utama. Rangkaian pembagi tegangan dipasang secara paralel pada tegangan output trafo yang berfungsi untuk membagi tegangan trafo menjadi beberapa bagian, sehingga pengukuran terhadap tegangan output trafo dapat dilakukan menggunakan voltmeter dengan tegangan maksimum rendah yang ditunjukan pada Persamaan (1):

$$
\mathrm{V}_{\text {Out trafo }}=\frac{R_{1}+R 2}{R_{2}} \times \text { Vvoltmeter }
$$

Penentuan rangkain pembagi tegangan dijelaskan pada Persamaan (2):

$$
\text { Daya }(\mathrm{P})=\frac{(V)^{2}}{R}=\frac{(7.5 k v)^{2}}{300 k \Omega}=187.5 \text { watt }
$$

Dengan 7,5 KV adalah asumsi tegangan output trafo yang keluar. maka daya yang dihitung sebesar 187,5 watt. Dan resistor yang dipakai sebesar 10 watt, 15k $\Omega$. Maka dibutuhkan sekitar 20 resistor untuk merangkai rangkaian pembagi tegangan. Sehingga didapatkan daya trafo setelah pembagian 20 resistor sebesar 9,34 watt. Dengan merangkai resistor secara seri sebanyak 20 buah dengan resistansi $15 \mathrm{k} \Omega$. Maka tegangan output yang didapatkan pada ujung pembagi tegangan ditunjukan pada Persamaan (3) dan Persamaan (4). 


$$
\begin{aligned}
& \mathrm{V}_{\text {out }}=\frac{R 1}{R 1+R 2} \times \mathrm{V}_{\text {out trafo }} \\
& \mathrm{V}_{\text {voltmeter }}=\frac{15 \mathrm{k} \Omega}{15 \mathrm{k} \Omega+285 \mathrm{k} \Omega} \times 7500 \mathrm{~V}=394,7 \text { volt }
\end{aligned}
$$

Dengan tegangan sebesar 394,7 Volt maka dapat menggunakan voltmeter dengan tegangan maksimal $600 \mathrm{~V}$. Pada pengukuran tegangan trafo ini menggunakan volt meter digital dengan tegangan maksimal yang dapat diukur sebesar $600 \mathrm{~V}$. penggunaan rangkaian pembagi tegangan bertujuan agar tegangan yang masuk untuk diukur oleh voltmeter tidak lebih dari $600 \mathrm{~V}$. Rangkaian regulator trafo mengatur tegangan output trafo pada tegangan $3000 \mathrm{~V}$ dan $4000 \mathrm{~V}$ dengan jarak antara batang konduktor (d) sebesar 0,3 cm.

\subsection{Indigo Kolorimeteri Sebagai Metoda Pengujian Hasil Konsentrasi Sisa Ozon}

Konsentrasi ozon yang terukur pada penelitian ini sebenarnya adalah konsentrasi sisa ozon karena ozon merupakan gas yang sangat reaktif. Keraktifan ozon menyulitkan bagi pengukuran kelarutan ozon didalam air secara langsung tanpa terjadi reaksi oksidasi dengan senyawa lain yang terdapat didalam air. Diperkirakan terjadi kehilangan konsentrasi ozon sekitar 10\% selama persiapan pengukuran (Hoigne dan bader, 1975)

Pengukuran konsentrasi sisa ozon terlarut dilakukan berdasarkan standart metode Indigo Colorimetric method (ICM) $\left(4500-O_{3}-B\right)$. Pengukuran dilakukan menggunakan spektrofotometer dengan panjang gelombang $600 \mathrm{~nm}$. Indigo yang digunakan dalam perhitungan konsentrasi sisa ozon adalah indigo trisulfonat. Pengukuran ozon dengan indigo dapat memberikan hasil yang akurat, mudah dan cepat. Karena reagen yang digunakan hanya mengandung satu ikatan karbon rangkap yang akan bereaksi dengan ozon. Metode indigo dapat digunakan untuk pengukuran konsentrasi ozon dari $0,005 \mathrm{mg} / \mathrm{L}$ hingga 30 $\mathrm{mg} / \mathrm{L}$.

Setelah pengukuran dengan spektrofotometer maka diperoleh data nilai absorban, yang kemudian dimasukan kedalam rumus sehingga nilai konsentrasi sisa ozon pada masing masing interval waktu kontak dapat diketahui. Rumus konsentrasi sisa ozon dapat dilihat pada Persamaan (5) :

$$
\mathrm{mgO}_{3} / \mathrm{L}=\frac{50 \times \Delta A}{f \times b \times V}
$$

Keterangan: $\Delta \mathrm{A} \quad$ : Selisih absorban antara sampel dan blanko

$$
\begin{aligned}
& \text { b : Panjang dari kuvet yang digunakan, } \mathrm{cm} \rightarrow 4,5 \mathrm{~cm} \\
& \mathrm{~V} \quad \text { : Volume sampel air, } \mathrm{mL} \rightarrow 45 \mathrm{~mL} \\
& \text { p } 0,42 \text { (didasarkan kepada faktor sensitifitas dari } 20.000 / \mathrm{cm} \text { untuk } \\
& \text { liter). }
\end{aligned}
$$

Dari hasil percobaan ini didapatkan grafik hubungan waktu kontak dengan konsentrasi sisa ozon pada setiap variasi penelitian.

\section{PENGUJIAN DAN ANALISIS}

\subsection{Pengukuran Tegangan Output Trafo}

Tegangan output trafo dihubungkan dengan rangkaian pembagi tegangan sebagai cara untuk membagi tegangan dan kemudian dihubungkan menuju alat ukur voltmeter. Hasil 
pengukuran pada volt meter menggunakan rumus pada Persamaan (1) ditunjukan pada Tabel 1.

Tabel1.Hasil pengukuran pada voltmeter

\begin{tabular}{|c|c|}
\hline $\begin{array}{c}\text { Pengukuran Pada } \\
\text { Voltmeter (Volt) }\end{array}$ & $\begin{array}{c}\text { Perhitungan } \\
\text { Tegangan } \\
\text { Output Trafo (V) }\end{array}$ \\
\hline $168,5 \mathrm{~V}$ & $3370 \mathrm{~V}$ \\
\hline $216,2 \mathrm{~V}$ & $4324 \mathrm{~V}$ \\
\hline
\end{tabular}

\subsection{Perhitungan Medan Listrik.}

Medan listrik diukur dengan membagi tegangan output trafo dengan jarak antar batang konduktor. Hasil perhitungan medan listrik ditunjukan pada Tabel 2 dengan menggunakan Persamaan (6)

$$
\mathrm{E}=\frac{\operatorname{Voltase}(\mathrm{Kv})}{d(\mathrm{~cm})}
$$

Tabel2.Hasil perhitungan pada medan listrik

\begin{tabular}{|c|c|}
\hline $\begin{array}{c}\text { Tegangan Output } \\
\text { Trafo (V) }\end{array}$ & $\begin{array}{c}\text { Medan } \\
(\mathbf{K v} / \mathbf{c m})\end{array}$ \\
\hline $3370 \mathrm{~V}$ & $11,2 \mathrm{Kv} / \mathrm{cm}$ \\
\hline $4324 \mathrm{~V}$ & $14,4 \mathrm{Kv} / \mathrm{cm}$ \\
\hline
\end{tabular}

\subsection{Hasil Pengujian Generator Ozon}

Pada pengujian dari perancangan generator ini terdapat beberapa jenis variabel pengujian yang digunakan, hal ini bertujuan untuk mengetahui hasil dari: Tegangan output trafo yang berhasil dibangkitkan sebesar $3370 \mathrm{~V}$ dan $4324 \mathrm{~V}$. Medan listrik yang dihitung berdasarkan tegangan output trafo sebesar $11,2 \mathrm{Kv} / \mathrm{cm}$ dan $14,4 \mathrm{Kv} / \mathrm{cm}$. Visualisasi Korona ditunjukan pada Gambar 6.

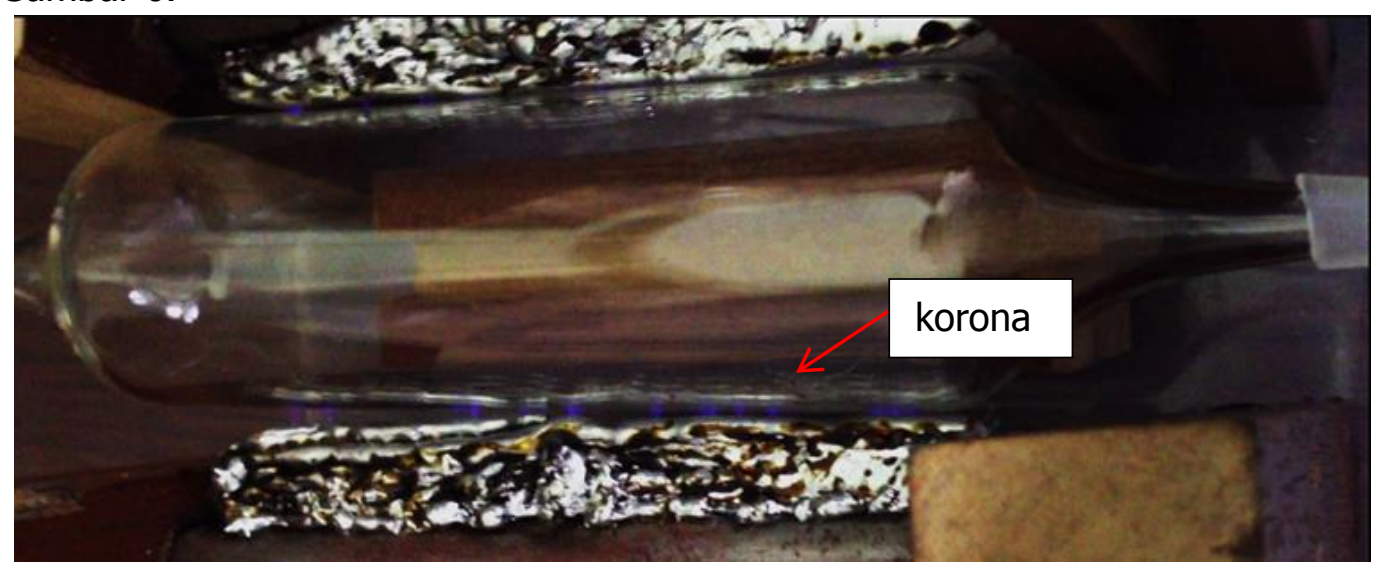

Gambar 6. Visualisasi Korona Pada Daerah Sekitar Reaktor Ozon Saat Generator Ozon Dihidupkan 
Laju oksigen yang dialirkan sebesar $1 \mathrm{~L} /$ menit dan $3 \mathrm{~L} /$ menit, Lamanya waktu pengontakan ozon terhadap air bersih dengan interval 5 menit hingga 30 menit ( 5,10,15,20,25,30 menit). Variasi yang dilakukan hanya bertujuan untuk membandingkan data konsentrasi sisa ozon yang didapat nantinya akibat perubahan variable. Semua variable diatas di uji coba untuk memperoleh data konsenstrasi sisa ozon terlarut didalam air bersih. Data yang ditampilkan merupakan data konsentrasi sisa ozon pada air bersih yang dilakukan dengan menggunakan metoda indigokolorimetri dan dibantu dengan spektrofoto meter. Perhitungan KSO didapat pada Persamaan (5).

\subsubsection{Pengujian Generator Ozon dengan laju oksigen 1L / menit}

Tabel 3. Hasil Pengukuran dan Perhitungan KSO dengan $Q=1 \mathrm{~L} /$ menit \& Tegangan $3370 \mathrm{~V}$

\begin{tabular}{|c|c|c|}
\hline \multicolumn{2}{|c|}{ Data Pengamatan 1L/menit } & \multirow{2}{*}{$\begin{array}{c}\text { Perhitungan } \\
\mathrm{KSO} \\
\left(\mathrm{mgO}_{3} / \mathrm{L}\right)\end{array}$} \\
\hline $\begin{array}{l}\text { Waktu } \\
\text { (menit) }\end{array}$ & $\begin{array}{c}\text { Pengukuran KSO } \\
\text { (A) }\end{array}$ & \\
\hline 5 & $-0,009$ & 0,013 \\
\hline 10 & $-0,008$ & 0,012 \\
\hline 15 & $-0,012$ & 0,018 \\
\hline 20 & $-0,013$ & 0,019 \\
\hline 25 & $-0,029$ & 0,043 \\
\hline 30 & $-0,038$ & 0,056 \\
\hline
\end{tabular}

Pada Tabel 3. dilakukan dengan cara membangkitkan tegangan tinggi sebesar 3370V dengan laju alir ozon sebesar 1L/menit. Pengambilan sampel air dari ozon kontaktor dilakukan setiap 5 menit selama 30 menit waktu pengontakan. Konsentrasi dihitung dengan menggunakan spektrofotometri saat pengambilan sampel pada setiap interval waktu. Pencatatan dilakukan sebanyak tiga kali dengan waktu interval dan sampel yang sama. Didapat konsentrasi sisa ozon terlarut terbesar yaitu $0.056 \mathrm{mgO}_{3} / \mathrm{L}$. Untuk data pengamatan pada tegangan $4324 \mathrm{~V}$ pada laju yang sama.

Tabel 4.Hasil Pengukuran dan Perhitungan KSO dengan Q=1L/menit\&Tegangan 4324V

\begin{tabular}{|c|c|c|}
\hline \multicolumn{2}{|c|}{ Data Pengamatan 1L/menit } & \multirow{2}{*}{$\begin{array}{c}\text { Perhitungan } \\
\mathrm{KSO}\left(\mathrm{mgO}_{3} / \mathrm{L}\right)\end{array}$} \\
\hline $\begin{array}{l}\text { Waktu } \\
\text { (menit) }\end{array}$ & Pengukuran KSO (A) & \\
\hline 5 & $-0,018$ & 0,026 \\
\hline 10 & $-0,022$ & 0,032 \\
\hline 15 & $-0,03$ & 0,044 \\
\hline 20 & $-0,04$ & 0,059 \\
\hline 25 & $-0,055$ & 0,081 \\
\hline 30 & $-0,06$ & 0,088 \\
\hline
\end{tabular}

Pada Tabel 4. dilakukan dengan cara membangkitkan tegangan tinggi sebesar $4324 \mathrm{~V}$ dengan laju alir ozon sebesar 1L/menit. Pengambilan sampel air dari ozon kontaktor dilakukan setiap 5 menit selama 30 menit waktu pengontakan. Konsentrasi dihitung dengan menggunakan spektrofotometri saat pengambilan sampel pada setiap interval waktu. 
Pencatatan dilakukan sebanyak tiga kali dengan waktu interval dan sampel yang sama. Didapat konsentrasi sisa ozon terlarut terbesar yaitu $0.088 \mathrm{mgO}_{3} / \mathrm{L}$.

\subsubsection{Pengujian Generator Ozon dengan laju oksigen 3L / menit}

Tabel 5. Hasil Pengukuran\& Perhitungan KSO dengan $Q=3 \mathrm{~L} /$ menit \& Tegangan $=3370 \mathrm{~V}$

\begin{tabular}{|c|c|c|}
\hline \multicolumn{2}{|c|}{ Data Pengamatan 3L/menit } & \multirow{2}{*}{ 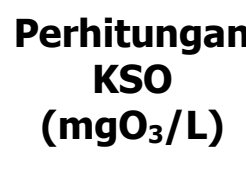 } \\
\hline $\begin{array}{l}\text { Waktu } \\
\text { (menit) }\end{array}$ & $\begin{array}{c}\text { Pengukuran KSO } \\
\text { (A) }\end{array}$ & \\
\hline 5 & 0,0017 & $-0,002$ \\
\hline 10 & $-0,001$ & 0,001 \\
\hline 15 & $-0,002$ & 0,003 \\
\hline 20 & $-0,004$ & 0,006 \\
\hline 25 & $-0,003$ & 0,004 \\
\hline 30 & $-0,008$ & 0,012 \\
\hline
\end{tabular}

Pada Tabel 5. dilakukan dengan cara membangkitkan tegangan tinggi sebesar $3370 \mathrm{~V}$ dengan laju alir ozon sebesar 3L/menit. Pengambilan sampel air dari ozon kontaktor dilakukan setiap 5 menit selama 30 menit waktu pengontakan. Konsentrasi dihitung dengan menggunakan spektrofotometri saat pengambilan sampel pada setiap interval waktu. Pencatatan dilakukan sebanyak tiga kali dengan waktu interval dan sampel yang sama. Didapat konsentrasi sisa ozon terlarut terbesar yaitu $0.032 \mathrm{mgO}_{3} / \mathrm{L}$.

Untuk data pengamatan pada tegangan 4324V dan kemudian dialirkan laju oksigen sebesar $3 \mathrm{~L} /$ menit dengan waktu pencatatan yang sama (30 menit dengan pencatatan data KSO per 5menit).

Tabel 6. Hasil Pengukuran \& Perhitungan KSO dengan $Q=1 \mathrm{~L} /$ menit \& Tegangan $=4324 \mathrm{~V}$

\begin{tabular}{|c|c|c|}
\hline \multicolumn{2}{|c|}{ Data Pengamatan 3L/MENIT } & \multirow{2}{*}{$\begin{array}{c}\text { Perhitungan } \\
\mathrm{KSO} \\
\left(\mathrm{mgO}_{3} / \mathrm{L}\right)\end{array}$} \\
\hline $\begin{array}{l}\text { Waktu } \\
\text { (menit) }\end{array}$ & Pengukuran KSO (A) & \\
\hline 5 & 0,0015 & $-0,002$ \\
\hline 10 & $-0,002$ & 0,003 \\
\hline 15 & $-0,008$ & 0,012 \\
\hline 20 & $-0,01$ & 0,015 \\
\hline 25 & $-0,02$ & 0,029 \\
\hline 30 & $-0,03$ & 0,044 \\
\hline
\end{tabular}

Pada Tabel 6. dilakukan dengan cara membangkitkan tegangan tinggi sebesar $3370 \mathrm{~V}$ dengan laju alir ozon sebesar 3L/menit. Pengambilan sampel air dari ozon kontaktor dilakukan setiap 5 menit selama 30 menit waktu pengontakan. Konsentrasi dihitung dengan menggunakan spektrofotometri saat pengambilan sampel pada setiap interval waktu. Pencatatan dilakukan sebanyak tiga kali dengan waktu interval dan sampel yang sama. Didapat konsentrasi sisa ozon terlarut terbesar yaitu $0.032 \mathrm{mgO}_{3} / \mathrm{L}$. 


\subsection{Grafik Hasil Pengujian Generator Ozon}

Konsentrasi sisa ozon yang didapat dari data diatas kemudian dapat ditampilkan pada grafik yang menunjukan konsentrasi sisa ozon yang terbentuk terhadap tegangan output yang dihasilkan, besarnya laju oksigen yang dialirkan, serta grafik yang menunjukan konsentrasi sisa ozon yang terbentuk terhadap lamanya waktu pengkontakan ozon.

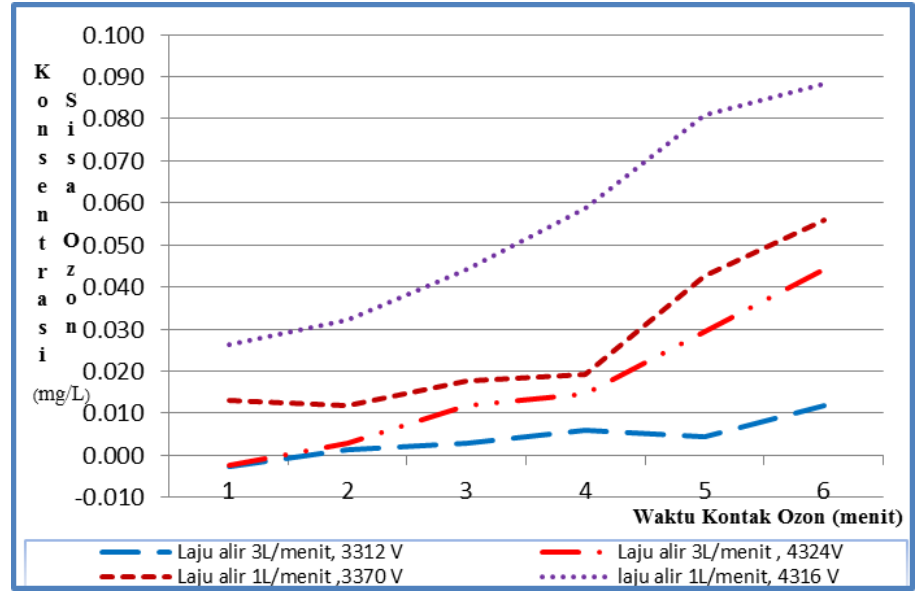

\section{Gambar 7.Grafik Hubungan Antara Waktu Ozonisasi Terhadap Konsentrasi Sisa Ozon Terlarut.}

Gambar 7. menunjukan grafik adanya peningkatan konsentrasi sisa ozon terhadap lamanya waktu pengontakan ozon. Konsentrasi sisa ozon tertinggi yang terbentuk pada variasi tegangan $4324 \mathrm{~V}$ dengan laju oksigen $1 \mathrm{~L} /$ menit sebesar $0.088 \mathrm{mgO}_{3} / \mathrm{L}$. Sedangkan hasil konsentrasi sisa ozon terendah terjadi pada tegangan 3370V dengan laju oksigen 3L./menit hanya menghasilkan $0.012 \mathrm{mgO}_{3} / \mathrm{L}$. Semakin lama waktu pengkotakan ozon pada air bersih, maka banyak ozon yang akan terlarut didalam air.

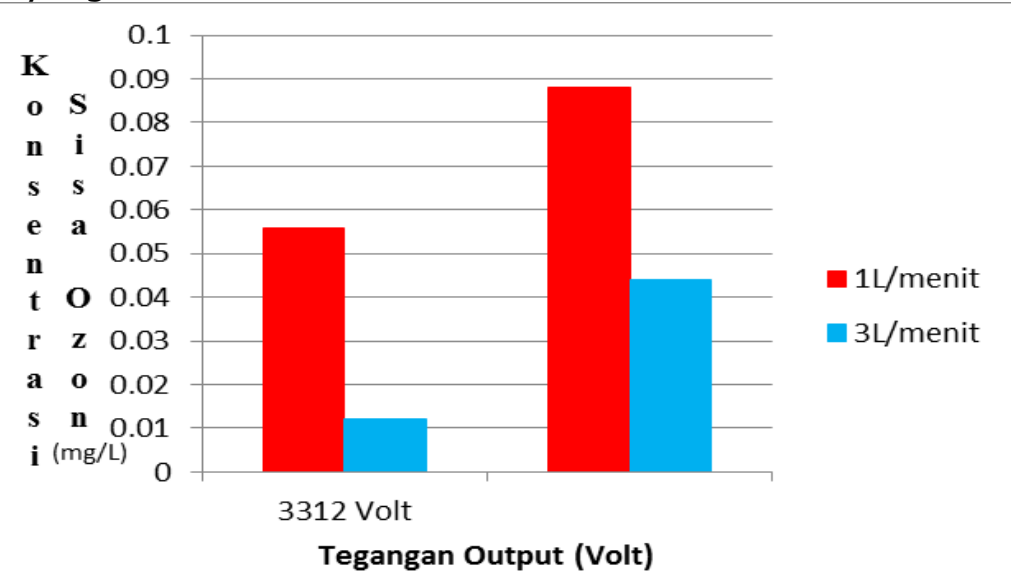

\section{Gambar 8. Grafik Hubungan Antara Pembangkitan Tegangan Tinggi Yang Dihasilkan Dengan Konsentrasi Sisa Ozon Terlarut}

Gambar 8. menunjukan grafik adanya peningkatan konsentrasi sisa ozon terhadap besarnya pembangkitan tegangan tinggi yang dihasilkan. kenaikan tegangan berbanding lurus terhadap kenaikan besarnya medan listrik yang terjadi. Terdapat kenaikan konsentrasi sisa ozon akibat perubahan tegangan tinggi yang dibangkitkan. Pada laju oksigen yang tetap (1L/menit) pada tegangan $3370 \mathrm{~V}$ dihasilkan konsentrasi sisa ozon sebesar $0.056 \mathrm{mgO} / \mathrm{L}$ sedangkan pada tegangan 4324 dihasilkan konsentrasi sisa ozon sebesar $0.088 \mathrm{mgO}_{3} / \mathrm{L}$. hal ini berlaku untuk laju alir oksigen sebesar 3L/menit. Pada tegangan $3370 \mathrm{~V}$ dihasilkan konsentrasi sisa ozon sebesar $0.032 \mathrm{mgO}_{3} / \mathrm{L}$. Pada tegangan $4324 \mathrm{~V}$ dihasilkan konsentrasi 
sisa ozon sebesar $0.044 \mathrm{mgO}_{3} / \mathrm{L}$. kenaikan Medan listrik yang dihasilkan oleh kenaikan pembangkitan tegangan tinggi menyebabkan semakin besarnya ikatan atom $O$ pada molekul oksigen yang terlepas sehingga membentuk ikatan ozon yang baru.

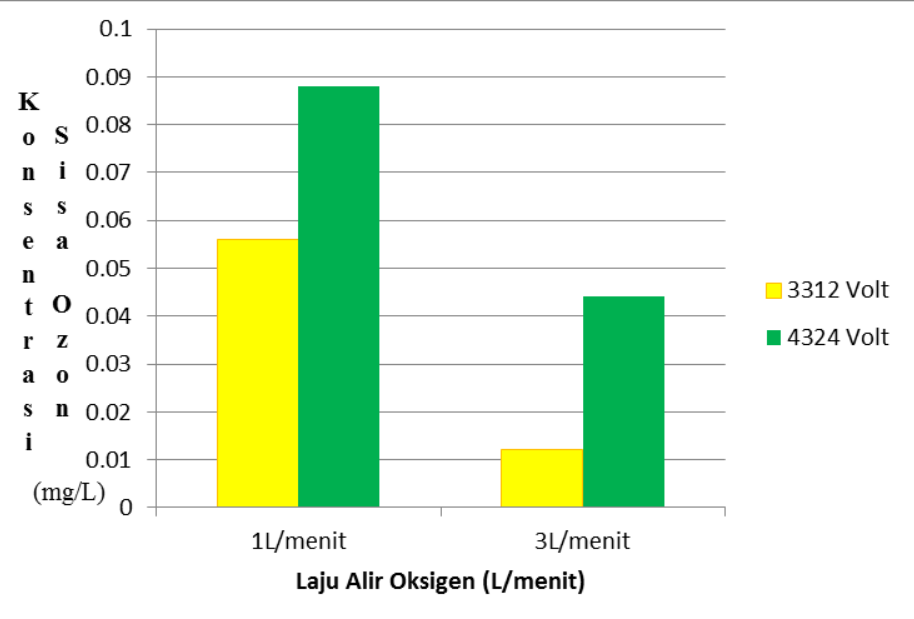

\section{Gambar 9.Grafik Hubungan Antara Laju Oksigen Yang di Berikan Dengan Konsentrasi Sisa Ozon Terlarut.}

Gambar 9. menunjukan grafik adanya peningkatan konsentrasi sisa ozon terhadap laju oksigen yang diberikan. Pada laju oksigen $1 \mathrm{~L} /$ menit pada tegangan $3370 \mathrm{~V}$ dihasilkan konsentrasi sisa ozon sebesar $0.056 \mathrm{mgO3} / \mathrm{L}$ sedangkan pada tegangan 4324 dihasilkan konsentrasi sisa ozon sebesar $0.088 \mathrm{mgO}_{3} / \mathrm{L}$. hal ini berbeda pada laju oksigen sebesar 3L/menit. Tidak terjadi kenaikan akibat kenaikan laju alir oksigen yang diberikan. Pada tegangan $3370 \mathrm{~V}$ dihasilkan konsentrasi sisa ozon sebesar $0.032 \mathrm{mgO}_{3} / \mathrm{L}$. Pada tegangan $4324 \mathrm{~V}$ dihasilkan konsentrasi sisa ozon sebesar $0.044 \mathrm{mgO}_{3} / \mathrm{L}$.

\subsection{Analisis}

Berdasarkan Gambar 7. grafik hubungan waktu ozonisasi dan laju alir terhadap konsentrasi sisa ozon terlarut menunjukkan lamanya pengkontakan ozon terhadap air berpengaruh terhadap konsentrasi sisa ozon $\left(\mathrm{O}_{3}\right)$ yang terbentuk. Dari grafik tersebut, dapat dilihat bahwa jumlah ozon $\left(\mathrm{O}_{3}\right)$ yang terbentuk paling besar pada saat laju alir oksigen 1 liter/menit, pada menit 5 dan tegangan 4324V volt sebesar $0.026 \mathrm{mgO}_{3} / \mathrm{L}$. Sedangkan pada kondisi yang sama dengan waktu yang berbeda, pada menit 30 konsentrasi sisa ozon yang terbentuk sebesar $0.088 \mathrm{mgO}_{3} / \mathrm{L}$. Semakin lamanya waktu kontak ozon terhadap air kran, maka konsentrasi sisa ozon yang terlarut didalam air semakin banyak. Peningkatan konsentrasi sisa ozon didalam air dikarenakan oleh banyaknya ozon yang larut didalam air dan kemudian ozon tersebut di tangkap oleh larutan indigo sehingga tidak terlepas kembali menjadi oksigen.

Pada Gambar 9. grafik hubungan antara laju oksigen yang di berikan dengan konsentrasi sisa ozon terlarut menunjukan bahwa pada saat tegangan yang diberikan tetap waktu pencatatan pada menit 30 dan perlakuan variasi laju alir oksigen diberikan kepada sistem generator(1L/menit dan 3L/menit), maka jumlah konsentrasi sisa ozon yang dihasilkan pada laju alir oksigen $1 \mathrm{~L} /$ menit pada tegangan $3312 \mathrm{~V}$ sebesar $0.056 \mathrm{mgO}_{3} / \mathrm{L}$ sedangkan pada laju alir oksigen sebesar 3L/menit pada tegangan yang sama dan waktu 30 menit didapat konsentrasi sisa ozon sebesar $0.012 \mathrm{mgO}_{3} / \mathrm{L}$. hal ini terjadi pada variasi tegangan sebesar $4316 \mathrm{~V}$ dengan waktu 30 menit. Pada laju alir oksigen sebesar 1L/menit didapat konsentrasi sisa ozon sebesar $0.088 \mathrm{mgO}_{3} / \mathrm{L}$. sedangkan pada laju alir sebesar $3 \mathrm{~L} /$ menit didapat konsentrasi sisa ozon sebesar $0.044 \mathrm{mgO}_{3} / \mathrm{L}$. konsentrasi sisa ozon terbesar didapat pada 
saat generator ozon diberikan laju alir oksigen sebesar $1 \mathrm{~L} /$ menit. Hal ini terkait dengan densitas/ rapat udara yang masuk kedalam generator. Dimana pada saat diberikan debit oksigen yang lebih kecil, maka densitas molekul menjadi lebih kecil sehingga jarak jalan bebas rata-rata masing-masing molekul untuk dapat bergerak menjadi lebih panjang. Sehingga menyebabkan transfer energi ketika terjadi tumbukan menjadi lebih efektif apabila dibandingkan dengan densitas yang lebih tinggi. Hal ini juga terkait karena proses pembentukan ozon adalah reaksi kesetimbangan: $3 \mathrm{O}_{2} \leftrightarrows 2 \mathrm{O}_{3}+298 \mathrm{kj}$

Reaksi tersebut berlangsung cepat dimana pereaksi pembatasnya ialah jumlah ozon $\left(\mathrm{O}_{3}\right)$ bukan jumlah oksigen $\left(\mathrm{O}_{2}\right)$. Jumlah ozone terbentuk tergantung dari ketersediaan energi potensial yang digunakan untuk mengubah oksigen $\left(\mathrm{O}_{2}\right)$ menjadi ozon $\left(\mathrm{O}_{3}\right)$ bukan banyaknya jumlah oksigen yang masuk kedalam generator ozon.

Pada Gambar 8. Medan listrik yang dihasilkan dengan melakukan variasi tegangan mempengaruhi besarnya hasil sisa konsentrasi ozon yang terlarut. Semakin besar tegangan trafo yang diberikan, maka kuat medan listrik yang dihasilkan semakin besar. Elektron yang berada pada tegangan tinggi cenderung bergerak dengan cepat, semakin tinggi perbedaan tegangan antar konduktor, semakin cepat elektron bergerak. Elektron yang bergerak akan bertabrakan dengan molekul udara dan terjadi ionisasi. Jika medan listrik yang timbul semakin besar. Akan semakin cepat mempengaruhi pelepasan ikatan antar atom $\mathrm{O}$ yang terikat pada senyawa O2. Pada hasil perancangan didapat medan yang terjadi pada daerah disekitar konduktor sebesar $\pm 11,2 \mathrm{Kv} / \mathrm{cm}$ dan $\pm 14,4 \mathrm{Kv} / \mathrm{cm}$

\section{KESIMPULAN DAN SARAN}

\subsection{Kesimpulan}

Dari penelitian ini dapat disimpulkan bahwa perancangan generator ozon dengan menggunakan metoda pembangkitan tegangan tinggi bolak balik telah selesai dibuat dan bekerja dengan baik. Berdasarkan pengujian, pengukuran dan analisa yang telah dilakukan, diperoleh beberapa kesimpulan sebagai berikut:

1. Banyaknya konsentrasi ozon yang terbentuk sebanding dengan waktu yang dibutuhkan untuk menghasilkan ozon. Semakin lama waktu pengontakan ozon, semakin bertambah konsestrasi sisa ozon pada air. Pada tegangan 3370V, laju oksigen 1L/menit, menit 5 didapat konsentrasi sisa ozon sebesar $0.013 \mathrm{mgO}_{3} / \mathrm{L}$. sedangkan pada menit 30 didapat konsentrasi sisa ozon sebesar $0.056 \mathrm{mgO}_{3} / \mathrm{L}$. Terdapat kenaikan konsentrasi sisa ozon didalam air pada tegangan yang sama dengan laju oksigen yang tetap sebesar 0.043 $\mathrm{mgO}_{3} / \mathrm{L}$. Hal ini berlaku untuk semua variasi waktu yang diberikan

2. Banyaknya konsentrasi ozon yang terbentuk sebanding dengan besarnya tegangan tinggi yang diberikan kepada generator ozon. Semakin besar tegangan yang dibangkitkan, maka medan listrik yang dihasilkan semakin besar. maka semakin besar hasil konsentrasi sisa ozon pada air. Pada laju oksigen yang tetap 1L/menit. Pada tegangan $3370 \mathrm{~V}$ dan menit 30 didapat konsentrasi sisa ozon pada air sebesar $0.056 \mathrm{mgO}_{3} / \mathrm{L}$. sedangkan pada tegangan $4316 \mathrm{~V}$ dengan laju oksigen yang sama pada menit 30 didapat konsentrasi sisa ozon sebesar $0.088 \mathrm{mgO}_{3} / \mathrm{L}$. Terdapat kenaikan konsentrasi sisa ozon didalam air pada laju oksigen yang tetap dengan tegangan yang berbeda sebesar $0.043 \mathrm{mgO}_{3} / \mathrm{L}$. Hal ini berlaku untuk semua variasi tegangan yang diberikan.

3. Semakin besarnya laju pengaliran oksigen maka konsentrasi sisa ozon yang didapat semakin berkurang. Pada laju oksigen 3L/menit dengan tegangan $4324 \mathrm{v}$ pada menit 30, didapat konsentrasi sisa ozon sebesar $0.026 \mathrm{mgO}_{3} / \mathrm{L}$, sedangkan pada laju oksigen 
$1 \mathrm{~L} /$ menit dengan tegangan sebesar $4324 \mathrm{~V}$ pada menit 30, didapat konsentrasi sisa ozon sebesar $0.088 \mathrm{mgO}_{3} / \mathrm{L}$. terdapat perbedaan konsentrasi sisa ozon sebesar $0.062 \mathrm{mgO}_{3} / \mathrm{L}$.

\subsection{Saran}

Adapun saran untuk pengembangan lebih lanjut sebagai berikut :

1. Untuk meningkatkan hasil produksi ozon dilakukan dengan mengubah konstruksi reaktor ozon. Perubahan bentuk pada batang konduktor yang berfungsi sebagai tempat pelucutan elektron berpengaruh terhadap hasil ozon yang didapat. Selain itu peningkatan tegangan tinggi pada rekator ozon juga berpengaruh pada hasil ozon

2. Untuk meningkatkan faktor keamanan, sebaiknya pada trafo dan reaktor ozon perlu diketanahkan. Hal ini bertujuan agar tidak timbul gradient tegangan antar peralatan dengan tanah yang dapat menyebabkan mengalirnya arus ke tanah jika terjadi tegangan sentuh.

3. Sebaiknya dilakukan pengujian laboratorium lebih lanjut untuk mengkaji lebih dalam mengenai kandungan ozon yang berhasil diproduksi oleh generator ozon yang telah rancang. Hal ini dikarenakan penggunaan teknologi ozon merupakan teknologi yang sangat bersih dan ramah lingkungan.

\section{DAFTAR RUJUKAN}

Purwadi Agus, UsadaWiddi, Suryadi, Isyuniarto,SriSukmajaya.(2002). Konstruksi Pembangkitan Ozon Bentuk Silinder Dengan Teknik Lucutan Senyap, Jogjakarta: Prosiding PPI - PDIPTN 2002 Puslitbang Teknologi Maju - BATAN,. ISSN 0216-3128

Purwadi Agus, UsadaWiddi, Suryadi, Isyuniarto, Mintolo.(2005).Plasma Ozonizer 20 W Terkendali Sederhana Untuk Penyimpanan Buah Dan Sayur, Jogjakarta : Prosiding Pertemuan dan Presentasi Ilmiah - Penelitian Dasar Ilmu Pengetahuan dan Teknologi Nuklir (Prosiding PPI - PDIPTN) 2005 Puslitbang Teknologi Maju - BATAN. ISSN 0216-3128

Yusuf Baharudin, Warsito Agung, Syakur Abdul, Widiasa I Nyoman.(2008).Aplikasi Pembangkit Tegangan Tinggi Impuls Untuk Pembuatan Reaktor Ozon, Semarang: Universitas Diponogoro.

Bimo, Wasito Agung,Syakur Abdul.(2011).Aplikasi Iginition Coil Sebagai Pembangkit Tegangan Tinggi Impuls Untuk Penyedia Daya Reaktor. Semarang: Universitas Diponogoro.

Angky Syafarudin, Novia. (2013). Produksi Ozon Dengan Bahan Baku Oksigen Menggunakan Alat Ozon Generator. Jurnal Teknik Kimia No.2 Vol. 19.

J Hoigne, Badder.(1994). Characterization Of Water Quality Criteria For Ozonation Processes Part II:Life Time Of Added Ozone, Ozone science and engineering, 16, 121-134

K.T Sirait, IR. R. Zoro, IR. Djoko Darwanto.(1987). Teknik Tegangan

Tinggi.Bandung:Laboratorium Teknik Tegangan Tinggi \& Pengukuran Listrik. Jurusan Teknik Elektro, Institut Teknologi Bandung.

Tim Humas dan Protokol PDAM Kota Bandung. (2007).Instalasi Pengolahan Air LimbahBojongsoang Pdam Kota Bandung. Bandung: PDAM Kota Bandung. 
Perancangan dan Realisasi Generator Ozon menggunakan Metoda Pembangkitan Tegangan Tinggi Bolak - Balik (AC)

Said, Idaman Nusa. (2008). Teknologi Pengelolaan Air Minum, Teori Dan Pengalaman Praktis. Jakarta: Pusat Teknologi di Lingkungan Deputi Bidang Teknologi Pengembangan Sumber Daya Alam. BPPT.

Ebbing, D.D, Gammon, S.D. (2009). General Chemistry. New York: Houghton Mifflin Company. 